\title{
HALK SAĞLIĞI YÖNÜNDEN OBEZITE
}

\author{
Meltem Çöl*
}

\section{ÖZET}

Obezite, özellikle gelişmiş ülkelerde çok yaygın olan bir sağlık problemidir. Türkiyede de çok yüksek prevalans oranları göstermektedir. Obezite pek çok hastalık için, özelliklede kardiyovasküler hastalıklar için önemli bir risk faktörüdür. Aynı zamanda mortalite riskini de arttırması nedeniyle obezite önemli bir halk sağlığı problemidir.

Epidemiyolojik çalışmalar için; beden kitle indeksi, bel-kalça oranı ve deri kıvrım kalınlığı ölçümü, obezitenin belirlenmesinde en uygun yöntemlerdir.

Obezitenin tedavisi uzun süre isteyen, güç ve pahalı bir işlem olup, korunmaya öncelik vermek gerekir.

Anahtar Sözcükler: Obezite, Epidemiyoloji, Halk sağ/ı̆̆ı

Obezite çok yaygın bir beslenme bozukluğu olup, çeşitli hastalıklara yol açması, yaşamı kısaltması ve tedavisi için pahalı bir sağlık hizmeti gerektirmesi açısından önemli bir sorundur. Obezitenin tanımı "vücuttaki yağ oranının artması" şeklinde yapılabilir $(1,2)$.

Vücut yağındaki değişim, enerji alımı ve enerji harcanması arasındaki dengesizliklere dayanır. Alınan enerji, harcanan enerjiden daha fazla olduğunda obezite gelişir(1,3). Bazı toplumların farklı obezite oranları göstermesi, genetik eğilimlerden ziyade diyet ve fiziksel aktivite gibi çevresel faktörlere bağlı gözükmektedir (1). Bu yüzden de toplumun çevresel koşullarını değiştirme yönündeki çalışmaların, toplumdaki obeziteye eğilimli kişilerin obez olma olasılıklarını azaltacağını söyleyebiliriz.

Obeziteyi diğer özellikleriyle ele almadan önce, ölçüm yöntemlerini belirlemede yarar vardır. Çünkü

SUMMARY
Obesity in Relation to Public Health
Obesity is very videspread health problem es-
pecially in developed countries. It has also very high
prevalance in Turkey. It is a major risk factor for
many illnesses especially for cardio-vascular dise-
ases. It also increases the risk of mortality, so it is
very important public health problem.
Body mass index, waist to hip ratio and skin-
fold thickness are the most suitable methods to de-
termine obesity, for epidemiological studies.
Treatment of obesity is long, difficult and ex-
pensive. We must pay attention primarily to prevent
from obesity.
Key Words: Obesity, Epidemiology, Public he-
alth

obezitenin dikkatli ve doğru bir şekilde teşhisi gerekir. Bu konuda kullanılan pekçok yöntem vardır. Bunlar;

- Yumuşak dokuda yağ kalınlığının X-ışını ile ölçümü

- Cilt yağ kalınlığının ultrasonografi ile ölçümü

- Toplam vücut su oranının ölçümü

- Vücut dansitesinin ölçümü, gibi pek de pratik olmayan yöntemlerdir.

Obezitenin belirlenmesi ve derecesinin tayini için ideal vücut ağırlığı kıstas alınarak değerlendirme yapılabilir. İdeal kilo hesaplamasında en çok kabul edilen formül Lorentz formülüdür. Bu formüle göre hesaplamalar şu şekilde yapılır:

Boy - 150

İdeal kilo $($ Erkek $)=$ Boy-100

4

* Doç.Dr., Ankara Üniversitesi Tıp Fakültesi Halk Sağlığı ABD Öğretim Üyesi 


$$
\text { İdeal kilo }(\text { Kadın })=\text { Boy }-100 \frac{\text { Boy }-150}{2}
$$

\% ideal vücut ağırlığının hesaplanması ise şu formülle yapılır.

$$
\text { \% ideal vücut ağırlığı }=\frac{\text { Gerçek ağırlık }}{\text { İdeal ağırlık }}
$$

İdeal vücut ağırlığının \%20 fazlası hafif, \%30-40 fazlası orta, \%40-50 fazlası ağır, \%50'den fazlası ise ağır obezite kabul edilir. Ayrıca obezitenin belirlenmesi için Rohrer, Ponderal, Benn, Broca gibi indekslerde kullanılmaktadır (4). Obezitenin belirlenmesinde kullanılan bu yöntemleri arttırmak mümkündür. Ancak bu yöntemlerden epidemiyolojik çalışmalar için en uygun ve pratik yöntem olarak deri kıvrım kalınlığı, beden-kitle indeksi ve bel-kalça oranı gibi yöntemler önerilmektedir (2).

\section{1) Deri kıvrım kalınlığı:}

Deri kıvrım kalınlığı vücutta 10 ayrı noktadan ölçülebilmekte ve bu ölçüm değerleri vücut yağ miktarının doğrudan göstergesi kabul edilmektedir. Bu ölçümler triceps, subscapular, biceps, suprailiac vb. bölgelerden "skinfold caliper" cihazı ile yapılmaktadır. Çalışmalar için genellikle sol subscapular yada sol triceps önerilmektedir $(2,3)$. Her deri kıvrım kalınlığı için ortalama değerler, yaşa göre persentil değerleri belirlenmiştir. Örneğin triceps ölçümünün 30-50 yaş arası erkeklerde $23 \mathrm{~mm}$, kadınlarda ise $30 \mathrm{~mm}$ 'den fazla olmaması gerekmektedir (4.).

\section{2) Beden-Kitle indeksi(BKi):}

Obezitenin ölçümünde en çok önerilen ve en yaygın kullanılan yöntemdir (5). Erişkinde artan boya göre artan ağırlık dikkate alındığından yararlıdır. Bu hesaplama aynı boyda olanlarda aynı oranda yağ dokusu bulunduğu varsayımına dayanır. Bu yüzden belirli bir boyda ağırlığın fazlalık derecesi saptanır (1). Formülü şu şekildedir;

$$
B K i=\frac{\text { Vücut ağırlığı }(\mathrm{Kg})}{\operatorname{Boy}^{2}\left(\mathrm{~m}^{2}\right)}
$$

BKI'ne göre yetişkinler için $B K i<20$ olanlar zayıf, $20-24,9$ arası normal, $25-29,9$ arası hafif obez(overweight), 30 - 39,9 arası obez, 40'ın üzeri ise ağır veya morbid obez olarak isimlendirilir. Bazı çalışmalar BKi sınırını 25 yerine 27 olarak kabul etse bile obezitenin belirlenmesinde önerilen ve en sık kullanılan sınır noktaları yukarıda belirtildiği gibidir (5). Bu belirleme- ler Kuzey Amerika ve Avrupa'daki uzun süreli epidemiyolojik çalışmalar ve yaşam istatistikleri temelinde yapılmıştır. BKI'nde normallik ve obezite sınırları risklere bağlı olarak ortaya konmuştur. Gelişmekte olan ülkelerde bu tür çalışma sonuçları olmasa da, pek çok toplumda obez kişilerin aynı komplikasyonları geliştirdiğine dair yeterli bilgi vardır. Bu yüzden de ileri ülkelerden elde edilen belirlemeler evrensel olarak kullanılabilir. Gelişmekte olan ülkelerde normallik alt sınırı için 20 yerine 18.5 kullanılması da bir alternatif olarak sunulmaktadır (1). Ancak yine de yaygın kullanım bu ülkeler için de alt sınırı 20 olarak kabul etmek şeklindedir.

BKI ve mortalite oranları her iki cinste hem sigara kullanan hem kullanmayanlarda karşılaştırıldığında U veya J şeklinde bir mortalite grafiği oluşmaktadır. Bu şekile göre BKi 20'nin altında olanlarda hafif bir risk artışı vardır. Ancak bu bölüm halen hasta olanları içermektedir ve risk artışı buna bağlanabilir. BKi için 20 24.9 arası ise iyi bir bölge olup en düşük mortalite oranı bu bölgede gözlenmektedir. Buna karşın BKi 25 29.9 arası bölge bir uyarı bölgesi olup, bu grupta sağlık sorunları artmakta ve ölüm oranlarında bir yükselme başlamaktadır. BKi 30 ve üzerinde olanlarda sağlık sorunları belirginleşmekte ve $40^{\prime} ı$ üzerine çıkanlarda da çok ciddi düzeyde risk artışı gözlenmektedir (1).

Çalışmalarda en çok tercih edilen BKi, deri kıvrım kalınlığı ile de çok uyumlu bulunmuştur. Ancak herhangi bir BKi'de vücut kompozisyonunda fark olabileceğini de gözardı etmemek gerekir. Düşük BKi'li bazı kişiler, yüksek BKi'liler kadar yağ içerebilir. Yaşa göre de bu oranda değişim olabilmektedir. Rosetta çalışması ve New Mexico Aging Process çalışmasına göre, daha ileri yaştaki erişkinlerin yaşla kas kaybına bağlı olarak, herhangi bir BKi'deki daha genç olanlardan daha fazla yağa sahip oldukları belirtilmektedir. Yani BKi'nin sınır noktasının sensitivitesi yaşla azalır (6). Bu yüzden tüm yaşlarda sabit noktalar kullanmak yerine yaşa özgü değerler kullanılması da bir çözüm olabilir.

\section{3) Bel-Kalça Oranı:}

Son zamanlarda bel-kalça oranı (waist to hip ratio; WHR) yağ dağılımını göstermede en iyi yol olarak kabul edilmekte ve kardiyovasküler hastalık riskini belirlemede diğer ölçümlerden daha değerli görülmektedir $(5,7)$. Bel çevresinin kalça çevresine bölünmesiyle elde edilen değerin erkeklerde $1^{\prime} \mathrm{i}$ kadınlarda ise $0.8^{\prime} i$ geçmemesi gerekir $(1,8)$. BKi sabit kalsa bile, bel-kalça oranındaki olumlu bir değişiklik riskin azalmasına neden olabilir. Çünkü bölgesel dağılım şişmanlığın derecesinden de bağımsız gözükmektedir. Bel-kalça oranı yüksek, üst kısmı şişman olanlarda Tip II diabet, hipertansiyon ve koroner kalp hastalığı daha fazla görülmektedir. 


\section{Çocuklarda obezitenin belirlenmesi:}

BKI'nin çocuk ve adolesanlarda kullanımı için persentil değerleri belirlenmiştir. Ancak BKi bu dönem obezitesinin belirlenmesinde çok geçerli görülmemektedir. Bel kalça oranı da çocuklarda uygun bir ölçüt değildir (7). Çocuklarda en fazla WHO - National Center for Health Statistics'in (NCHS) standartları kullanılmaktadır (1). Ayrıca bazı ülkelerde kendilerine özgü birtakım standartlar geliştirmiştir.

Adolesanlarda değerlendirme daha güçtür. Çünkü pubertal döneme geçildiğinde vücut kompozisyonu ve ağırlık hızlı bir değişime girmektedir. Bu dönem için de $\mathrm{FAO}$ ve WHO'nun boya göre ağırlık temelinde standartları kullanılmaktadır.

\section{Obezite Prevelansı:}

Obezite, malnütrisyonun en yaygın formlarından biridir. Obezite prevalansını değerlendirirken ulusal çaptaki çalışmalar az olduğu için bölgesel çalışmalardan yararlanılmaktadır. Günümüzde $A B D^{\prime}$ de 13 milyon morbid obez bulunduğu bildirilmektedir (9). Değişik sınır noktaları ve kriterler kullanılması nedeniyle çalışmalar arasında prevalans yönünden karşılaştırma yapılması güç olmakla birlikte özellikle gelişmiş ülkelerde çok yaygın bir sorun olduğu bilinmektedir. Erişkin nüfusun \%20-40'ının, çocuk ve adolesanların da $\% 10-20$ 'sinin obez olduğu bildirilmekte olup, İngiltere'de 50-59 yaş grubunda kadınların $\% 64$ 'ü, erkeklerin \%60'ı obezdir $(2,10)$. İtalya' da yapılan bir çalışmada 6-13 yaş arası çocukların \%5.8'inin, Kanada'da yapılan benzer bir çalışmada ise 5-13 yaş grubu çocukların \%8'inin obez olduğu saptanmıştır (2).

Türkiye'de 1974 Ulusal Beslenme Araştırması'na göre erişkin erkeklerin \%26.4'ü fazla kilolu, \%7.6'sı obez, kadınların \%38.5'i fazla kilolu, \%25.6'sı obez bulunmuştur(11). Ankara Üniversitesi Tıp Fakültesi Halk Sağlığı Anabilimdalı́nın araştırma bölgesi olan Park Sağlık Ocağı bölgesinde 40 yaş üzeri nüfusta kadınların \%41.1'i hafif obez (fazla kilolu), \%28.8'i obez, erkeklerin ise \%36'sı hafif obez, \%5.43'ü obez bulunmuştur (12). Diyarbakırda ve Malatya'da yapılan bölgesel çalışmalarda kadınların yaklaşık \%80'inde BKi 25' in üzerinde bulunmuştur $(13,14)$. Benzeri birçok çalışma göstermektedir ki obezite ülkemiz için de oldukça yaygın bir sağlık sorunudur.

Cins olarak kadınlarda daha fazla görülen obezite yaş olarak ta ileri yaşlarda artmaktadır. Çünkü yaş ilerledikçe fizik aktivite azalmakta, ancak yemek yeme alışkanlığı pek değişmemektedir. Yapılan araştırmalarda obezitenin özellikle 30-60 yaş arasında pik yaptığı dikkati çekmektedir (10). Obezite daha çok gelişmiş ülkelerde ve bu ülke toplumlarının sosyo-ekonomik düzeyi düşük kesimlerinde yüksek prevalans göstermektedir (2). Obezite kısa ve orta boylularda uzun boylulara göre daha çok gözlenmektedir (15).

\section{Obezite Nedenleri:}

Obezite etyolojisinde birçok faktör rol oynamakla birlikte enerji alımını arttıran ve fiziksel aktiviteyi azaltan sosyal ve çevresel faktörler en önemli etkenlerdir. Toplumlar modernleştikçe daha mekanize hale gelmekte ve enerji harcamayı gerektiren işler azalmaktadır. Fizik aktivitenin azalmasına karşın damağa hitap eden yüksek enerjili besinlerin tüketimi de artmaktadır (2).

Yapılan çalışmalar göstermektedir ki diyetteki yağ oranı obezite etyolojisinde önemli bir etkendir $(1,16)$. Psikolojik nedenlerle aşırı yemek yenmesıde önemli bir obezite nedenidir (3).

Obezite gelişiminde genetik eğilimler de sözkonusudur. Aynı genetik yapıya sahip olanlarda vücut yağında benzer değişiklikler gösterme eğilimi olduğu ikizler üzerinde yapılan çalışmalarla gösterilmiştir (17). Hem genetik eğilimler ḥemde ailenin beslenme alışkanlıkları vb. çevresel faktörler beraberce etki ederek obezite olasılığını arttırmaktadır. Mayer, obezite için var olan \%10 şansın, 1 ebeveyn obezse \%50'ye, 2 ebeveyn de obezse \%80'e çıktığını belirtmektedir (2).

Obezite gelişiminde çocukluk obezitesinin de önemi vardır. Özellikle kızlarda çocukluk obezitesinin daha büyük ölçüde kalıcı olduğu gözlenmektedir. Çocukluk obezitesinin gelişiminde de infant dönemdeki beslenme etkili olmaktadır. Bu dönemdeki diyetin yağ hücrelerini etkilediği ve gelecekteki obezite olasıı̆ı̆ını arttırdığı şeklinde hipotezler vardır ve erken dönemdeki obezitenin solid gıdalara erken geçme veya az emzirmeyle de ilişkisine dikkat çekilmektedir (2). Puberte dönemindeki kilo alımları ise daha geçici etkiler yapmaktadır. Bunların dışında birçok metabolik ve hormonal bozukluklar sonucu da obezite meydana gelebilmektedir.

\section{Obezitenin riskleri:}

Obezitenin oluşturduğu sağlık riskleri, onu önemli bir halk sağlığı sorunu olarak ele almamızı gerektirmektedir. Obezitenin yol açtığı veya etkili olduğu pekçok sağık sorunu olmakla birlikte bunların içinde kalp-damar hastalıkları belki de en önemlisidir. Qbezite, kalp-damar hastalıkları için bağımsız bir risk faktörü olarak kabul edilmektedir. Framingham kalp çalışması ve Evans County çalışmaları başlangıç ağırlığı ve kilo alımı ile kalp hastalığı arasında kuvvetli bir ilişki bulmuştur. Framingham çalışmasında 25 yaştan sonra kilo almanın özellikle ani ölüm ve angina ile daha çok ilişkili olduğuna dikkat çekilmektedir (2). Her iki çalışmada da obezlerde hipertansiyon gelişme riski fazla bulunmuştur. Çalışma sonuçları kan basıncı ve koroner kalp hastalığı için en yüksek riskin çocuklukta zayıf olup, erişkinlikte kilo alanlarda olduğunu 
ve özellikle abdominal bölgede yı̆̆ılmanın önemli olduğunu göstermektedir $(18,19,20)$.

Erkekler, karın yağlanmaları olduğu için(android tip obezite) daha fazla riskli durumdadır. Kadınlarda ise gluteal-femoral yağlanma hakimdir ki (jinoid tip obezite) bu o kadar önemli bir risk getirmemektedir (17).

Obezitenin trombo-embolik strokla da yakından ilişkili olduğu uzun süreli takip çalışmaları sonucunda gösterilmiştir (21). Obezlerde tip II diabet riski de artmaktadır (3). Framingham çalışmasında \%0.7 olan diabet insidansı \%20 fazla ağırlıklı olanlarda \%2, \%50 fazla ağırlıklı olanlarda \%10'a çıkmıştır.

Obezite ayrıca safra taşı, post-menapozal dönemde meme-ca, cerrahi ve anestezi risklerini, deri enfeksiyonlarını arttırmakta, obezlerde psikolojik bozukluklar, osteoporoz, solunum sistemi problemleri, jinekolojik problemler, kazalar daha yüksek oranda ortaya çıkmaktadır $(1,11,22,23)$.

Sonuç olarak obezite hem sosyal bir hastalık, hemde mortaliteyi büyük oranda etkileyen gerçek tıb- bi bir problemdir. Özellikle BKi 40'dan fazla olanlarda mortalite riski çok yükselmektedir (9).

\section{Obezitenin kontrolü:}

Obezitenin kontrolü için hemen tüm sağlık problemlerinde olduğu gibi, sorunun belirlenmesi ve korunma öncelik taşımaktadır. Obezite tedavisi uzun olup çeşitli güçlükler içermektedir. Bu yüzden koruyucu yaklaşımların öncelik taşımasına karşılık, yüksek prevelanslı ülkelerde tedavisi de önem kazanmaktadır.

Toplum eğitiminde fazla beslenmenin az beslenme kadar olumsuz olduğu anlaşılır hale getirilmelidir. Toplumların besin tüketim alışkanlıkları değerlendirilmeli, yeterli ve dengeli beslenmenin sağlanabilmesi için besin politikaları da yeniden gözden geçirilmelidir.

Tedavide temel nokta enerji alımının azaltılması, enerji harcamanın arttırılmasıdır. Bu noktada davranışların değiştirilmesi önem gösterir (24). Uzun ve güç olan tedavi sırasında diyet, egzersiz psikiatrik yardım ve sosyal destek kombinasyonu sağlanmalıdır. Ancak diyet, bilinçli yapılmadığında çeşitli sağlık riskleri olduğu da unutulmamalıdır.

\section{KAYNAKLAR}

1. WHO Technical report series, No:797, Diet, nutrition and the prevention of chronic diseases. Report of a WHO study group. Geneva 1990.

2. Osancova K, and Hegda S. Epidemiology of Obesity. In Obesity; It's pathogenesis and management. Edited by Silverstone T. Chapter III, p:57-87. Medical and Technical Publishing Co Ltd. 1975, Lancaster, England.

3. Scrimshaw SN, and Wray DJ. Nutrition and preventive medicine in "Last JM. Maxcy-Rosenau Public Health and Preventive Medicine. 11th Edit. 1475-7 New-York 1980.

4. Pekcan G. Şişmanlık ve saptama yöntemleri. İ̧̧inde: Şişmanlık ve çeșitli hastalıklarla etkileşimi ve diyet tedavisinde bilimsel uygulamalar. Derl. Árslan P. Türkiye Diyetisyenler Derneği Yayını: 4;7-37 Ankara 1993.

5. Hodge AM, Zimmet PZ. International Diabetes Institute, Caulfield, Victoria, Australia. The epidemiology of obesity.Baillieres Clin Endocrinol Metab. 1994 Jul. 8(3)57799.

6. Baumgartner RN, Heymsfield SB, Roche AF. Human body composition and the epidemiology of chronic disease. Obes Res. 1995 Jan. 3(1)73-95.

7. Moussa MA, Skaik MB, Selwanes SB, Yaghy OY, Bin-Othman SA:Contribution of body fat and fat pattern to blood pressure level in school children.Eur J Clin Nutr. 1994 Aug. 48(8)587-90.

8. Emmioğlu G. Beden-Kitle indeksi ile kan lipidleri, açlık kan şekeri, kan basıncı ve antropometrik parametreler arasındaki ilişkiler üzerine bir araştırma. Hacettepe Universitesi Sağlık Bilimleri Enstitüsü, Beslenme ve Diyetetik Programı Bilim Uzmanlığı Tezi. Ankara 1991

9. Laville M. Definition and epidemiology of massive obesity: Rev Prat. 1993 Oct 1. 43(15)1905-7.

10. Yavuz S. Çubuk Merkez Sağlık Ocağı bölgesinde erişkin grupta obezite prevalansı ve bunu etkileyen etkenlerin saptanması. Hacettepe Universitesi Sağlık Bilimleri Enstitüsü, Beslenme ve Gıda Bilimleri Programı Bilim Uzmanlığı Tezi. Ankara 1986.

11. Köksal O. Türkiye 1974 Beslenme, sağlık ve gıda tüketimi araştırması. Hacettepe Üniversitesi, Ankara-1977.

12. Çöl M. Park sağlık ocağı bölgesinde 40 yaş üstü nüfusta hipertansiyon prevelansı ve etkili faktörler. Uzmanlık tezi, Ankara Universitesi Tıp Fakültesi Halk Sağlığı Anabilimdalı 1990-Ankara.

13. Toksöz P, Ertem M, Saka G, Ceylan A. Kadınlarda şişmanlık görülme sıklığı ve bunu etkileyen etmenlerin analizi. Halk Sağlığı Günleri, Beslenme sorunları ve yasal durum. Bịldiri özet kitabı. 8-10 Eylül 1997, Süleyman Demirel Üniversitesi Tıp Fakültesi Halk Sá̆lığı Anabilimdalı, Isparta.

14. Güneş G, Genç M, Pehlivan E. Yeşilyurt sağlık ocağı bölgesindeki erişkin kadınlarda obezite. V.Halk sağlığı günleri, beslenme sorunları ve yasal durum. Bildiri özet kitabı, 8-10 Eylül 1997, Süleyman Demirel Unniversitesi Tıp Fakültesi Halk Sağlı́̆ı Anabilimdalı, Isparta

15. Freeman JV, Power C, Rodgers B. Weight-for-height indices of adiposity: relationships with height in childhood and early adult life. Int J Epidemiol. 1995 Oct. 24(5)970-6.

16. Lissner L, Heitmann BL. Dietary fat and obesity: evidence from epidemiology. Eur j Clin Nutr. 1995 Feb. 49(2). P 79-90.

17. Despres JP, Moorjani S, Lupien PJ, Tremblay A, Nadeau A, Bouchard C. Genetic aspects of susceptibility to obesity and related dyslipidemias. Mol Cell Biochem. 1992 Aug 18. $113(2) 151-69$.

18. Holm SS, Sorensen TIA, Jensen G and Schnohr P. Independent effect of weight change and attained body weight on prevalence of arterial hypertension in obese and nonobese-men. B M J 1989 (299); 767-70.

19. Tyroler HA. Epidemiology of hypertension as a public health problem. An overview as background for evaluation of blood lead - blood pressure relationship. Environmentalhealth perspectives. 1988 (78);3-7.

20. Ramsay LA: Obesity and hypertension. Proceed Sat Symp. $11^{\text {th }}$ Scientific meeting. ISH, Titisee-Neustadt, Nephron. 1987(47);5-7(Suppl)

21. Abbott RD, Behrens GR, Sharp DS, Rodriguez BL, Burchfiel CM, Ross GW, Yano K, Curb JD. Body mass index and thromboembolic stroke in nonsmoking men in older middle age. The Honolulu Heart Program.Stroke. 1994 Dec. 25(12) 2370-6.

22. Chie WC, Chen CF, Lee WC, Chen CJ. Body size and risk of pre- and post-menopausal breast cancer in Taiwan. Anticancer Res. 1996 Sep-Oct. 16 (5B)3129-32.

23. Choban PS, Heckler R, Burge JC; Flancbaum L. Increased incidence of nosocomial infections in obese surgical patients. Am Surg. 1995 Nov. 61(11)1001-5.

24. Tanaka K, Nakanishi T. Obesity as a risk factor for various diseases: necessity of lifestyle changes for healthy aging. Appl Human Sci. 1996 Jul. 15(4).139-48. 